\title{
INDIOS DE ARRIBA EN SANTIAGO DE CHILE SEGÚN LOS REGISTROS DE BAUTISMO: ENTRE EL AUGE ESCLAVISTA, LA RECONSTRUCCIÓN URBANA Y EL ABOLICIONISMO (1665-1685)
}

\author{
INDIANS FROM ARRIBA IN SANTIAGO DE CHILE ACCORDING TO \\ THE BAPTISM RECORDS: BETWEEN THE RISE OF SLAVERY, URBAN \\ RECONSTRUCTION AND ABOLITIONISM (1665-1685)
}

\author{
Jaime Valenzuela Márquez ${ }^{1}$
}

\begin{abstract}
Este artículo busca relevar el peso cuantitativo de la presencia de inmigrantes indígenas de Chile meridional, especialmente mapuches y huilliches esclavizados, en la ciudad de Santiago. El estudio se basa en el análisis de los registros de bautismo celebrados en la parroquia del Sagrario y se sitúa en una coyuntura histórica de transición entre el auge de captura y tráfico de indios "rebeldes", y la abolición de su esclavitud legal. La hipótesis central busca relacionar la tensión histórica de ambas tendencias, con la crisis demográfica que se abrió en Santiago a raíz del descenso de la población indígena durante el período 1647-1670, y con el aumento de la demanda por mano de obra masculina, para las obras públicas, y femenina e infantil, para el servicio doméstico de una creciente y urbanizada población hispanocriolla.
\end{abstract}

Palabras claves: Mapuches y huilliches, esclavitud indígena, registros parroquiales, Santiago de Chile, siglo XVII, historia urbana.

This article seeks to highlight the quantitative weight of the presence of indigenous immigrants from southern Chile -enslaved Mapuche and Huilliches particularly-in the city of Santiago. The study is based on an analysis of the records of baptisms celebrated in the parish of the Sagrario and is situated in a historical period of transition between the rise of the trafficking and captive-taking of the "rebel" Indians and the abolition of legal slavery. The central hypothesis seeks to relate this apparent contradiction to the demographic crisis that took place in Santiago, due to the decline of the indigenous population between 1647 and 1670, and to the increasing demand for both male labor, for public works, and women and children, for domestic service, in an increasingly urbanized Hispanic population.

Key words: Mapuches and Huilliches, Indian slavery, parish records, Santiago de Chile, 17th Century, urban history.

\section{La Deportación Auca: Antecedentes y Contexto}

Junto con las primeras resistencias armadas de los promaucaes maulinos y, sobre todo, de los mapuches meridionales, los hispanos comenzaron a reproducir en Chile las estrategias represivas y prácticas esclavistas que venían implementando desde sus primeros pasos por las Antillas caribeñas. Prácticas que cobrarían renovado impulso a raíz de la guerra desatada en 1598-1604 y, luego, con la cédula real que en 1608 autorizó la captura y transacción legal de los indios de Arriba -al sur del río Biobío- que se mantuviesen en "guerra viva".
El secuestro, deportación y esclavización de mapuches araucanos, huilliches osorninos y valdivianos, e incluso puelches y chonos -capturados desde Chiloé o Valdivia- no solo adquirió, así, un estatus formal, sino que además se transformó en el verdadero motor de las razzias "guerrilleras" -malocas - que articularon la guerra meridional, y el principal objetivo de los soldados fronterizos y de sus aliados indígenas (Boccara 2007 [1998]:327330; Ruiz 1998; Urbina 2009:75-106; Valenzuela 2009:237-241).

Nuestro análisis se vincula con un campo de estudio de fuerte desarrollo desde hace más de tres décadas, y donde la investigación histórica

\footnotetext{
$\overline{1}$ Instituto de Historia, Pontificia Universidad Católica de Chile, Casilla 306, Correo 22, Santiago, Chile. jvalenzm@uc.cl
} 
sobre fronteras americanas -incluyendo la llamada New Western History - se ha venido alimentando con perspectivas de las otras ciencias sociales y con objetos de estudio complementarios, como las relaciones interétnicas, el poder político, los desplazamientos humanos, la esclavitud y la historia urbana (Bernand 2001; Giudicelli 2011; Malone 1989).

En el plano local, el período tratado permite articular dos tendencias virtualmente opuestas: por un lado, la maduración y fortalecimiento coyuntural del tráfico esclavista; por otro, su decadencia o metamorfosis. Se trata de una tensión que podríamos delimitar en su inicio con la guerra hispano-mapuche de 1655-1662, de particular virulencia, y que reactivó la captura y tráfico de esclavos así como los fundamentos esgrimidos por los actores locales para llevarla a cabo. Pero que, al mismo tiempo, coincidió con el comienzo de una política abolicionista de amplitud imperial, que abarcó también a otros espacios fronterizos donde se conservaba esta anacrónica práctica (Reséndez 2013). Para el caso chileno, esta tendencia fue inaugurada en 1656 por Felipe IV, que prohibió transar indios libres a cambio de bienes entregados a sus parientes -"venta a la usanza"-, continuada con varias cédulas que entre 1662 y 1667 buscaron erradicar el tráfico de indios de Arriba hacia el Perú e incentivar la restitución a sus tierras, y coronada con la cédula de 1674 que pretendió la abolición definitiva (Hanisch 1981).

No obstante, y en abierta contradicción con esta tendencia legal, buena parte de esas disposiciones coincidieron con un refuerzo de las malocas y del tráfico de indios esclavos hacia Chile central y la región agrominera de Coquimbo. Coincidencia directamente relacionada con dos de los gobernadores que más incidencia tuvieron en su mantención e incentivo: Francisco de Meneses (1664-1668) y Juan Henríquez (1670-1682). Ambos se caracterizaron, además, por incrementar las razzias ya no solo contra indios hostiles, sino también contra parcialidades de "amigos". En el juicio de residencia a Meneses, sin ir más lejos, se ventilaron numerosos casos de indios capturados ilegalmente y luego vendidos para su beneficio personal, repartidos como retribución a sus cercanos o retenidos para servir directamente en su hogar (Juicio de residencia a Francisco de Meneses, Santiago, 1669, AGI, EC, sección 83, vol. 937, fjs. 76v-77, 78-79, 172 y 180). Una práctica similar habría desarrollado el gobernador
Henríquez, quien, por cierto, actuó diligentemente para dilatar la promulgación de la cédula de 1674 . De hecho, pese a otra cédula de 1679 que ordenaba su inmediato cumplimiento, finalmente la Corona cedió a las presiones locales y en 1686 optó por confirmar la práctica del "depósito", que mantenía a los exesclavos con sus antiguos amos o los reasignaba a otros en calidad de encomendados (Jara y Pinto 1982-1983, I:319-351; Obregón y Zavala 2009) ${ }^{1}$.

Junto con lo anterior, y como parte del conjunto de indios de Arriba que migraban hacia el norte del Biobío, debemos considerar la arraigada y generalizada costumbre de "sacar" niñas o muchachos indios para trasladarlos a otro lugar a trabajar en diversas tareas, sin ningún sustento jurídico; eran simplemente "tomados" y "llevados" por algún español o mestizo desde la frontera araucana, Chiloé o regiones cercanas pero ya colonizadas, como Chillán o Maule (Contreras 2013); o bien intercambiándolos a sus familias por algún objeto o comida. A estos indios e indias "sueltas" debemos agregar, desde el último tercio del XVII, a quienes migran en busca de trabajo remunerado en la construcción o mantención de los fuertes, o cruzan el Biobío para concentrarse en obras urbanas de la ciudad de Concepción o como peones de estancia en tierras de Chillán o Maule. Muchos de ellos son indios "amigos", cuyos periplos migratorios se confunden con el vagabundaje y la errancia, pero que pueden ser interrumpidos temporal o permanentemente por arraigos laborales y formalizados, como los que podían ofrecer las labores productivas de una ciudad como Santiago (Contreras 2005-2006; Góngora 1966; Méndez 1987; Ruiz-Esquide 1993).

\section{Los Registros de Bautismo: Fuente y Posibilidades}

La importancia demográfica de estos fenómenos es muy difícil de cuantificar, sobre todo para el caso de los indios "sueltos". Para el caso de los esclavos existen testimonios cualitativos y algunas referencias numéricas generales que nos permiten vislumbrar la magnitud que pudo haber alcanzado su tráfico, al menos para períodos anteriores al que aquí presentamos, si bien basados generalmente en información fragmentaria (Jara 1984 [1961]; Villalobos 1995:93 y 100).

Es por ello que nuestro análisis lo hemos basado en un sustrato empírico suficientemente sólido como son los registros parroquiales que, en principio, 
debían inscribir sistemáticamente el bautizo cristiano tanto de recién nacidos como de adultos "infieles", como era el caso de aquellos inmigrantes "sacados de su gentilidad" desde el sur del Biobío. Se trata de un tipo de documentación desarrollada en la Europa bajomedieval como una forma de marcar la pertenencia individual a la Iglesia y, por ende, a la comunidad "civilizada", delimitando con ello una barrera explícita en relación con los que se encontraban fuera de la cultura cristiana (Prosperi 2006:17). Pero será con las conclusiones del Concilio de Trento cuando el catolicismo del siglo XVI, junto con refrendar su estructura administrativa y la función de los ritos sacramentales, fijará la obligación de dejar por escrito y en libros separados la administración de bautismos, matrimonios y defunciones. La complejidad americana y la obsesión de distinción de los ibéricos llevó, por su parte, a que se dispusiera una separación de los libros entre “españoles” y el resto -indios, mestizos, negros y mulatos- (Carrasco 1858 [1688]:41-42).

Si bien la historiografía ha constatado desfases e incumplimientos importantes en la aplicación local de estas disposiciones eclesiásticas, lo que llevaría a la existencia de subregistros demográficos de consideración (Castillo 2008:65-76; Konetzke 1946; Mellafe 1986; Ogass 2013; Rabell 1990), no es menos cierto que para el caso de los indios de Arriba que nos ocupan estos problemas no deberían ser tan invalidantes como para otros bautizados. Esto, pues su proveniencia geográfica - de tierras de "enemigos"los marcaba desde el momento mismo de su destierro con una representación "superestructural"

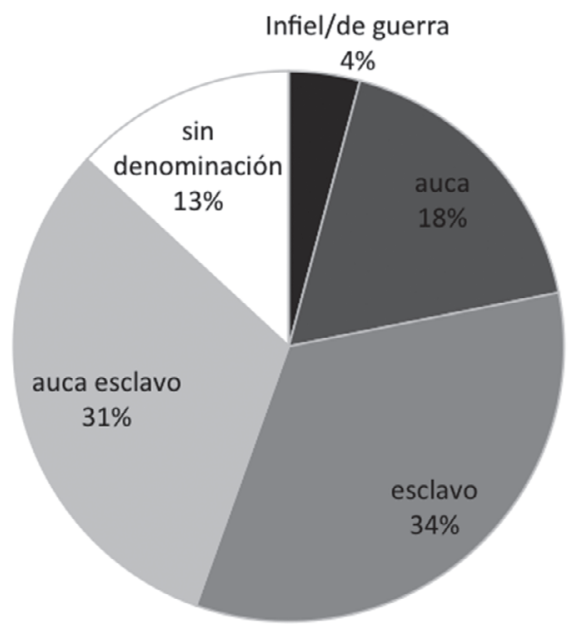

Figura 1. Denominaciones de indios de Arriba: bautizados y sus padres (El Sagrario, 1665-1685).

Denominations of Indians from Arriba: baptized and their parents. Fuentes utilizadas: AAS, Sag, libros 0, 7, 8, 9, 10 y 21. que definía su identidad jurídica y, por lo mismo, las denominaciones con que invariablemente aparecerán en los registros parroquiales (auca, "infiel", "de guerra", "de tierra adentro e hijo de padres infieles", etc.). De hecho, la gran mayoría de bautizados de Arriba en el Sagrario de Santiago durante la segunda mitad del XVII son producto de una inmigración forzada o son hijos de padres que han llegado a Santiago por esa vía; y solo en el 13\% que no poseen denominación podrían encontrarse inmigrantes sureños "sueltos" o "libres" (Figura 1).

Por otro lado, los libros de bautismo son, dentro de los registros sacramentales y otras fuentes demográficas del período, los que pueden otorgar mayor sistematicidad y detalle de los individuos. Por lo mismo, permiten un seguimiento más seriado, afinando la observación sobre los ritmos específicos de los flujos migratorios, el detalle de sus cantidades y la posibilidad de desglose de sus orígenes geográficos y distribución etaria.

Se revisaron, pues, todas las partidas de bautismo de indígenas en la parroquia del Sagrario, situada en la iglesia mayor de la ciudad. Sobre esta base elegimos el corte temporal 1665-1685, pues no solo contenía partidas mensuales relativamente completas, sino que además coincidía con un aumento significativo en el número de sujetos, una coyuntura especialmente importante en la historia de la esclavitud de indios sureños -entre auge y abolición- y con una serie de condiciones específicas que estaba viviendo la ciudad de Santiago en relación con su infraestructura y el mercado de trabajo, como veremos más adelante (Figura 2$)^{2}$.

\section{Tendencias Demográficas}

Antes de observar el período que nos convoca, creemos necesario constatar que el porcentaje de inmigrantes de Arriba bautizados en el Sagrario ya era importante en una década preesclavista como 1585-1595, fluctuando entre $20 \%$ y $35 \%$ del total de indios que recibieron el sacramento, lo que permite confirmar tanto su peso demográfico en la ciudad, como la vigencia y amplitud geográfica de la temprana deportación ilegal (Jara 1984 [1961]; AAS, Sag, libros 0, 1, 2 y 3). Armando de Ramón confirma esta relación, calculando que entre el último tercio del siglo XVI y la primera década del XVII, más de dos tercios de los indígenas que conformaban la población urbana $-70 \%$ de la población de Santiago- no eran originarios de su distrito, proviniendo la mayoría de ellos de la zona Arauco-Osorno (De Ramón 1965). 


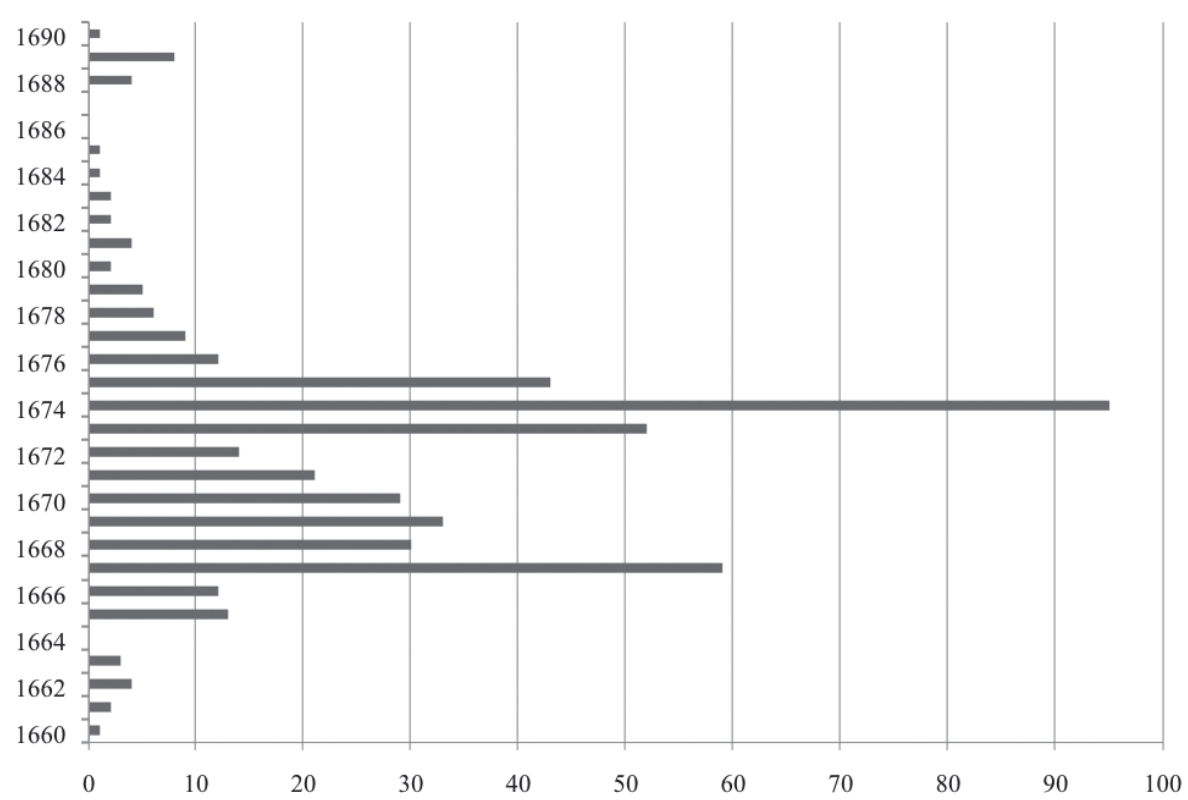

Figura 2. Número de indios de Arriba bautizados, por año, en El Sagrario (1660-1690). Number of baptized Indians from Arriba, per year, in El Sagrario. Fuentes utilizadas: AAS, Sag, libros 0, 2, 6, 7, 8, 9, 10 y 21.

Esta relación se mantenía hacia finales del siglo, como lo constata el mismo De Ramón al señalar que para el período 1681-1695 los indios de Arriba equivaldrían al $25 \%$ del total de indios bautizados en esa misma parroquia. No obstante, para esta época su peso demográfico ya sería menor, considerando que el conjunto de "indios" -con toda la subjetividad y polisemia que revestía esta denominación en el contexto de las dinámicas coloniales-había descendido de aquel $70 \%$ a cerca del $20 \%$ de la población bautizada total de la ciudad (De Ramón 1978:77-78). Y si bien dentro de este total se mantenía una fuerte proporción de "forasteros" (57\%), la mayoría de ellos ahora provenían del valle central, mientras que buena parte de los que se declaraban originarios de Arriba formaban parte de los derroteros individuales a los que nos hemos referido antes.

Por cierto, sin duda que el contexto abolicionista que comenzó a imponerse en el último tercio del XVII debió influir en esta recomposición de los inmigrantes, así como el aumento sostenido del mestizaje biológico y la circulación incontrolada de sujetos de toda índole, que alimentarán el mundo del peonaje asalariado del siglo siguiente.

Pero ciertamente que esta observación global respecto del descenso de la población indígena de Santiago adquiere una dimensión diferente si observamos la relación porcentual que se encuentra en la Figura 3 y, sobre todo, al descomponer en forma desglosada su evolución cronológica a lo largo de la segunda mitad del siglo. Así, vemos cómo entre 1665 y 1675 el bautizo de indios de Arriba que poseen la categoría de "esclavo" o auca aumenta y se mantiene en torno al 30\% anual del total de indios bautizados de la ciudad. Se trata de una coyuntura que debemos analizarla en forma específica, sobre todo porque antes y después de ella la relación es notoriamente menor (5-10\%). En guarismos absolutos, ello se traduce en que durante aquella década se bautizaron 401 indios de Arriba, mientras que en la década que la precede (1654-1664) fueron apenas 28 y en la que la sucede (1676-1686) solo 44 indios.

\section{Mano de Obra para Santiago... Después de la Catástrofe}

La capital chilena, isla urbana en medio de un valle central marcado por la ruralidad, la dispersión demográfica y la fragilidad de la administración estatal y eclesiástica, se convertirá en un destino privilegiado para un universo de sujetos con orígenes 


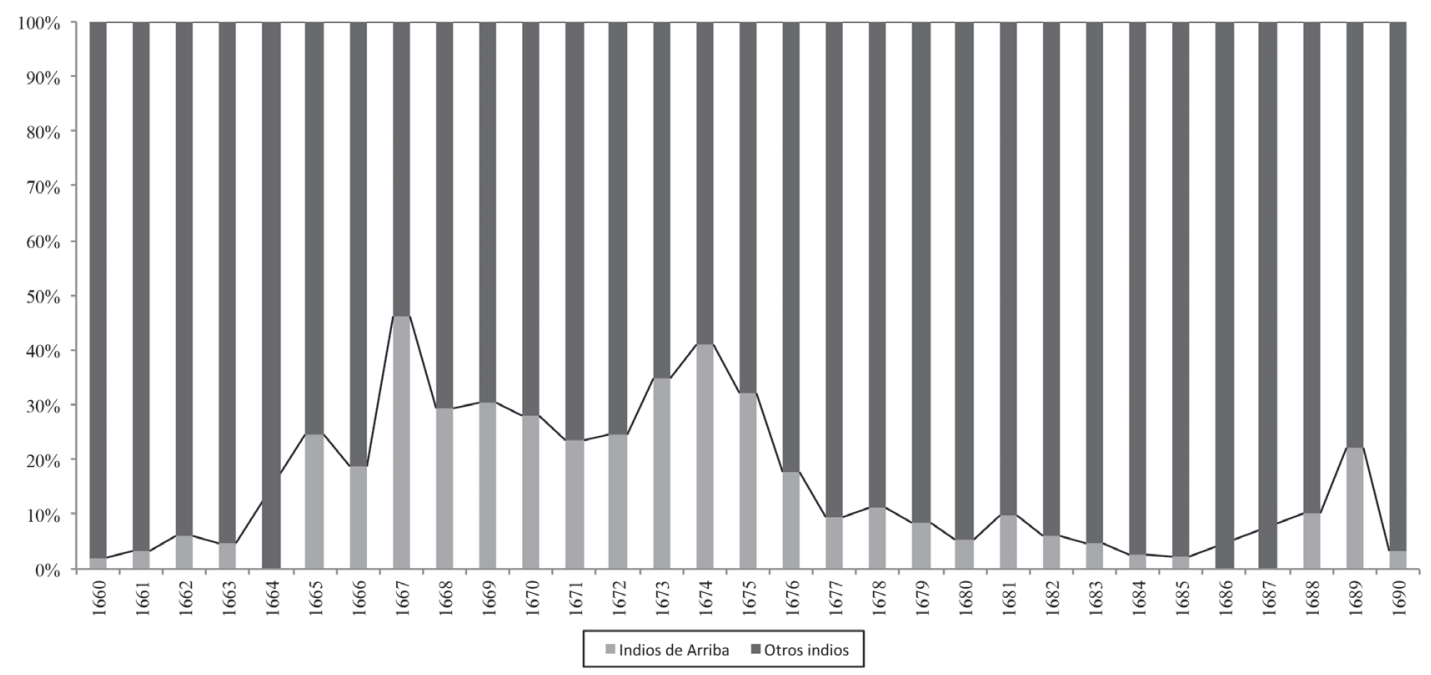

Figura 3. Relación entre indios de Arriba y total de indios bautizados por año en El Sagrario (1660-1690).

Rate of Indians from Arriba in the overall amount of Indians baptized per year in El Sagrario.

Fuentes utilizadas: AAS, Sag, libros 0, 2, 6, 7, 8, 9, 10 y 21.

geográficos y étnicos muy diversos. Inmigraciones vinculadas, entre otros factores, a la demanda de servicios domésticos, obras públicas y privadas, y producción artesanal características de la complejidad económica y social de las concentraciones urbanas coloniales (Hoberman y Socolow 1992).

De ahí que al estudiar la presencia de indios de Arriba en Santiago no solo debemos preocuparnos por las características y condiciones en las que se generó la emigración -la guerra esclavista del sur-, sino también aquellas en que se generó la demanda que alimentó dicho tráfico. Es fundamental, entonces, preguntarse por las fluctuaciones demográficas locales, especialmente por la caída de población nativa que afectó a Santiago en los prolegómenos de la coyuntura que estudiamos.

En efecto, en 1647 ocurrió un devastador terremoto que asoló el valle central y que tuvo particular incidencia en la capital (Valenzuela 2007). El sismo destruyó prácticamente todas las viviendas e infraestructura urbana y habría causado la muerte directa de un $25 \%$ de su población, siendo en su mayor parte "gente de servicio" y niños, y que a juicio del Cabildo era un "número grande, respecto de la poca gente que hay" (Acta de 18 de enero de 1648,

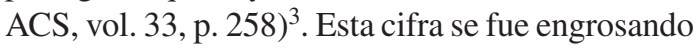
con posterioridad gracias a diversas pandemias que no cesaron de brotar entre su población, como el tifus, que dos años más tarde ya había cobrado otras dos mil víctimas en la comarca santiaguina, siendo su mayor parte de "la gente servil trabajada (sic) y la más necesaria para el sustento de la república, crianzas y labranzas" (Real Audiencia al rey, Santiago, 12 de julio de 1648 y 22 de mayo de 1649, BNCh, BMM, vol. 140, fjs. 125 y 153). A comienzos de 1650 los muertos habían llegado a duplicar la cifra del año anterior, alcanzando ya "más de cuatro mil personas del servicio de indios y negros que nos sustentaban" (Cabildo al rey, Santiago, 26 de enero de 1650, BNCh, BMM, vol. 140, fjs. 188-190). Por esa fecha aparecía una nueva epidemia, de viruelas, que siguió devastando la población al menos hasta 1653 ... y a fines de esta década reapareció el tifus, que solo amainó hacia 1671.

El impacto negativo en la disponibilidad de mano de obra fue detectado ya al año siguiente del terremoto, cuando el Cabildo informaba al monarca sobre las dificultades para la reconstrucción debido a que "no hay indios ni esclavos que se puedan ocupar en este ministerio, porque antes del temblor había pocos [...] y [en] el murieron muchos, y después acá ha padecido el lugar un género de peste que en esta gente de servicio ha obrado con rigor" (Cabildo al rey, Santiago, 6 de julio de 1648, BNCh, BMM, vol. 140, fjs. 38-39). Ya a fines de la década de 1650 el descenso de la población "de servicio" 
llegó a ser tan alarmante que su recuperación solo se estimaba posible si se permitía importar los esclavos negros que se decomisaban en Buenos Aires, donde llegaban de contrabando por hallarse prohibida su internación a través de ese puerto (Real Audiencia al rey, Santiago, junio de 1659, BNCh, BMM, vol. 145, fj. 110; Obispo de Santiago al rey, Santiago, 16 de marzo de 1664, BNCh, BMM, vol. 147, fjs. 39-46).

Aunque efectivamente se reactivó la tendencia al crecimiento que venía experimentando la población de origen africano en Santiago desde antes del sismo (Zúñiga 2006), no es menos cierto que la importación de esclavos negros siguió siendo muy costosa por la ruta del Pacífico -Callao- y riesgosa por la ruta continental -Buenos Aires-(Mellafe 1984 [1959]:240-256), además de que seguían teniendo valores que doblaban o incluso triplicaban al de los esclavos indios locales (Soto 2011:96-97; Zúñiga 2002:374). Por lo demás, estos últimos no solo eran más baratos, sino que, ya terminada la guerra hispano-mapuche de 1655-1662, se encontraban más asequibles.

De esta forma, la frontera del sur pudo seguir proporcionando importantes cantidades de indios de Arriba, con un ritmo que tiene su correlato en los registros de bautismo de la ciudad y que estaba en directa relación con una coyuntura demográfica caracterizada por la compulsión de trabajadores para intentar reconstruir la urbe, tanto en lo que respecta a casas particulares y conventos de religiosos como sobre todo a obras públicas de envergadura. Un proceso que demoró varias décadas, durante las cuales vecinos, autoridades y eclesiásticos vivirán y ejercerán sus labores en estructuras provisorias. De hecho, fue justamente durante el período que estamos estudiando cuando se dio el impulso más sostenido a las principales obras de la ciudad, que en 1657 había vuelto a sufrir otro embate similar, derrumbando lo poco que se había logrado rehacer en esos años (Cabildo al virrey del Perú, Santiago, 17 de marzo de 1657, ACS, vol. 35:261).

Recién a partir de 1667 se comenzaría una reconstrucción más sistemática y definitiva de la ciudad -al menos en lo que respecta a obras públicas-, de la mano con la rehabilitación del impuesto de balanza $a^{4}$, que había sido suprimido a raíz del terremoto, pero que ahora la Corona restablecía para ser orientado exclusivamente a estos trabajos (acta del Cabildo, 15 de julio de 1667, ACS, vol. 37, pp. 180-181). Entre las edificaciones que se van concretando durante los últimos años de la década de 1670 destacan las estructuras sólidas y definitivas -de cal y canto- para el tajamar del Mapocho y el puente sobre el río Maipo -en la entrada sur al valle de Santiago-, y el nuevo inmueble para el Cabildo (actas del Cabildo, 1 de octubre de 1668, ACS, vol. 37, p. 288; 23 de marzo y 22 de octubre de 1677, ACS, vol. 40, pp. 103 y 167; 9 de marzo, 2 de septiembre y 26 de noviembre de 1678, ACS, vol. 40, pp. 203, 245 y 263-264).

Aunque las fuentes no muestran una relación generalizada entre el aumento de la llegada de indios forzados de Arriba y su ocupación en los trabajos de reconstrucción urbana, sí presentan indicios que podrían apuntar en esa dirección. Entre ellos, podemos mencionar el caso de la catedral de Santiago, cuyos trabajos se retomaron durante el obispado de Diego de Humanzoro (1662-1676), ahora con vistas a un edificio definitivo, y para lo cual se comenzó a demandar la obra de mano indígena incluso de encomiendas locales (De Ramón 2002:120-130) ${ }^{5}$.

Pues bien, contamos con el registro de cuentas de la obra de la catedral para los años 1665-1667 y allí podemos encontrar el recibo cobrado por un maestro herrero para "hacer prisiones a cuatro indios aucaes que se pusieron en la obra de la iglesia", y que al parecer habían sido asignados directamente por el propio gobernador Meneses. También hay otro recibo por el gasto en hierro para fabricar dos prisiones para otros cuatro "indios aucaes para que trabajasen en la iglesia, las cuales prisiones eran de cadena" (recibo de 18 de diciembre de 1665, y descargos de cuentas, 11 de julio de 1668, ANHCh, RA, vol. 2905, fjs. 42, 51-51v). Valga una digresión para relevar este concepto de "prisión" y el uso de la coerción asociada al trabajo forzado como punición -por haberse "alzado" contra la soberanía real-y a la condición de esclavitud; lo que nos lleva a la estrecha vinculación entre la administración de justicia, los sistemas de trabajo y las formas de reparación social vigentes en la época ${ }^{6}$. De hecho, aunque sin mencionar si iban dirigidas a aucaes o a otros sujetos, el documento anterior también menciona el pago de otros recibos por cantidades importantes de hierro "para hacer prisiones [...] para el beneficio y labor de la iglesia" (fj. 51v). Sin ir más lejos, en 1668 el obispo escribía a Madrid para quejarse del abandono en que el gobernador Meneses tenía la obra -en medio de la tensión que enfrentaba a ambas autoridades- señalando que "la dejó tan desamparada que ni un indio de los 
esclavos de v[uestra] maj[estad] quiso dejar en ella y aún los que por la justicia estaban condenados a trabajar en ella, se los quitó y llevó donde quiso" (Diego de Humanzoro a la reina regente, Santiago, 16 de mayo de 1668, Lizana 1919, I:279).

La fábrica de la catedral tuvo un ritmo más intenso desde 1667 hasta su término en 1670, período en el cual encontramos numerosas partidas parroquiales que registran a bautizados o a padres de niños bautizados de Arriba que se hallaban destinados a esta construcción. En febrero de 1669, por ejemplo, varios aucaes que habían sido traídos recientemente a la capital estaban asignados a esta obra, como lo indica el bautismo simultáneo de al menos cinco de sus hijos: una niña de cinco años del cacique Nilatilo -"de los que trabajan en la obra de la iglesia"-; otro de tres años, hijo del cacique don Bartolo -"que trabaja en la obra desta iglesia"-; una pequeña de cinco meses, hija de Alonso y Leonor -"indios de los aucas deste Reino de los que trabajan en la Iglesia"-; Matheo de cuatro años y Francisca de cinco años -ambos de "padres indios infieles que trabajan en la Iglesia"- (AAS, Sag, libro 8, fjs. 62-62v).

\section{Mujeres y Niños para el Servicio Doméstico}

Si bien se trata de sujetos que no están directamente involucrados en las ocupaciones descritas con anterioridad, la documentación parroquial permite acercarnos a un universo humano que era sin duda cuantitativamente mayoritario y que, en el caso femenino, tendió a aumentar su proporción en el período que nos ocupa (Figura 4).

El trabajo doméstico constituía el espacio predilecto para ocupar mujeres "de servicio", en una ciudad cuya población hispanocriolla no solo no sufrió el mismo rigor pandémico que los grupos subalternos, sino que tendió a incrementar su peso demográfico, más que duplicando el número de sus bautizos entre los períodos 1645-1665 y 1665-1685 (De Ramón 1978:88 y 159; Zúñiga 2002:100).

Chile reprodujo una larga tradición continental del "botín de guerra" femenino practicado desde la conquista, y donde la mayoría de las mujeres terminaba como sirvientes sexuales, criadas, nodrizas o cocineras de estancieros, soldados y religiosos. Entre estos últimos, por ejemplo, el sínodo celebrado en Santiago en 1688, al prohibir cualquier trato sospechoso entre curas y mujeres, declaraba explícitamente que se debía evitar "el servirse en sus casas de mujeres mozas, así españolas como indias [...], y no traer a su casa, con ningún pretexto, chinas muchachas -según el vocablo quechua que designaba a las niñas menores de edad" (Carrasco 1858 [1688]:34). No obstante, el propio obispo que encabezó este sínodo había aparecido algunos años antes bautizando a dos indias de 8 y 15 años, caracterizadas como "natural de las provincias de arriba, hija de padres infieles", y que estaban a su servicio (partidas de bautismo, abril de 1681, AAS, Sag, libro 10, fjs. 147-147v).

Junto con las mujeres adultas, pues, las niñas, niños y adolescentes tendían a ser los preferidos en las razias esclavistas del sur y también en los secuestros individuales y las "compras" "a la usanza”. Por mencionar el juicio de residencia al gobernador Meneses, citado más arriba, podemos ver que de las 146 "piezas" que, para su beneficio, se vendieron en Santiago durante el período de su gobierno, la mayor parte fueron, justamente, chinas e indias "con su crío" (Residencia de Francisco de Meneses, Santiago, 1669, AGI, EC, sección 83, vol. 937, fjs. 261-265).

En efecto, la mujer esclava presentaba la ventaja jurídica adicional de que su propietario podía vender el derecho a la servidumbre de sus

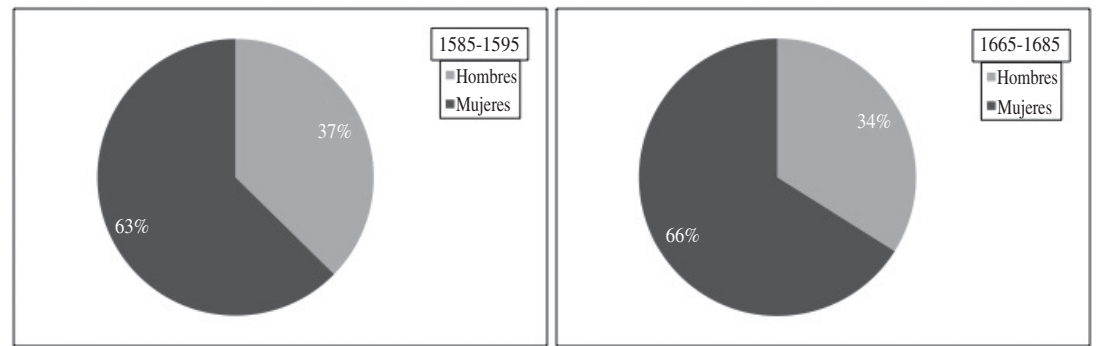

Figura 4. Relación de género de los indios de Arriba bautizados en El Sagrario (1585-1595 / 1665-1685). Gender rate of Indians from Arriba baptized in El Sagrario. Fuentes utilizadas: AAS, Sag, libros 0, 7, 8, 9, 10 y 21. 
hijos y, en general, de todos los procreados por línea umbilical o agnaticia (Muñoz 2003:127). Los infantes y "muchachos", por su parte, tenían ventajas comparativas para una inversión a largo plazo: no solo su precio era menor -en el caso de los esclavos-, sino que también eran más fáciles de "sacar" desde el seno familiar -intercambiándolos por una vaca o hierro- o simplemente "tomándolos" al paso, por soldados o sus aliados indígenas ${ }^{7}$. Por otro lado, y a diferencia de los adultos, también eran más fáciles de "aclimatar" a las nuevas condiciones de vida y a las formas culturales occidentales -lengua, religión y hábitos-y, por lo mismo, era más difícil su huida (Valenzuela 2009:249-255).

Todos estos antecedentes y tendencias se confirman para el caso de nuestro sujeto de estudio. En la Tabla 1 vemos que durante el período analizado fueron en su mayoría mujeres, pero sobre todo las pequeñas, quienes recibieron este sacramento en la principal pila bautismal de la capital. Así, de las 139 mujeres que registran alguna información respecto de su edad, solo 12 tendrían más de 30 años, mientras que 60 aparecen con menos de 20 años (43\%). Más aún, esta última cifra podría aumentar significativamente si consideramos la constante ambigüedad con que en la época se revestían las categorías de "adulto", "muchacho/a" y "china", por mencionar algunas de las principales denominaciones que, a falta de datos precisos, hemos incluido en el grupo "sin información", pero que esconderían una cantidad aparentemente importante de sujetos por debajo de los 10 años de edad. Algo que sería aún más evidente en el caso de las llamadas "chinitas", que normalmente tendían a ser de no más de 6 años (cf. Noli 1998).

De esta forma, un recorrido por las partidas de esos años permite apreciar diferencias importantes, por ejemplo, entre indios calificados por el cura como "adulto" y que, al mismo tiempo, aparecen con una edad estimativa. Entre estos se encuentran personas de 40 o 50 años, pero también muchas de entre 15 y 20 años; e incluso hay varios de menos de 10 . La adultez se confundía, pues, con lo que podríamos definir como adolescencia, e incluso frisaba la niñez; a lo que contribuía el hecho de que la edad laboral indígena-sobre todo la forzada y esclava- también comenzaba al finalizar la primera década de vida. Sin ir más lejos, los primeros diccionarios españoles restringen la definición de "niño" a los menores de siete años, siguiendo con ello la representación europea sobre el período de la primera dentición (Real Academia Española 1734:669; Ariès 1987
[1960]:41); mientras que en el comercio de esclavos negros de Ciudad de México la edad de siete años se tomaba como referencia para saber cuándo se podía separar a un niño de su madre y venderlo por separado (Masferrer 2011:200).

\section{Conclusiones}

Hemos visto cómo la inmigración de indígenas provenientes de allende el Biobío mantiene la tendencia de épocas anteriores e incluso tiende a aumentar hacia fines de la década de 1660 y durante la de 1670. Esto, en medio de una coyuntura tensionada por el despertar de las políticas abolicionistas que promovía la monarquía respecto de las esclavitudes amerindias que aún persistían en algunas de sus fronteras y, por otro lado, la demanda creciente de mano de obra por parte de la sociedad hispanocriolla de Santiago. Una ciudad que comenzaba a tener más recursos, que necesitaba reconstruir su infraestructura y responder a los requerimientos terciarios -ampliando, por ejemplo, el segmento de mano de obra no calificada entre los artesanos- y hortícolas - potenciando los cultivos de sus chacras periurbanas-, dinámicas propias de un crecimiento como el que se estaba experimentando en esos años; $y$, por lo mismo, una ciudad con creciente demanda de servicio doméstico para los cada vez más numerosos hogares "españoles".

La satisfacción de estas demandas se dio en buena medida por los desplazamientos individuales y voluntarios de indígenas sureños que cruzaban hacia el norte, se contrataban en Concepción o erraban hacia Chile central, donde terminan vinculados con sus actividades. También hay que considerar el aumento que se observa en la población negra, mulata y, sobre todo mestiza, que por esos años comienza un inexorable crecimiento demográfico.

Sin embargo, como lo hemos mostrado en las páginas anteriores, la decadencia de la guerra maloquera contra los indios del sur no terminó en 1662 -según postula Villalobos- como tampoco la demanda y el tráfico de esclavos de Arriba (Villalobos 1995:62). De hecho, y en relación con la importancia que se le seguía asignando dentro de la fuerza laboral de Santiago y su comarca, baste con señalar que desde las primeras noticias que se recibieron en Santiago sobre la cédula de 1674 que abolía su esclavitud, la élite, representada por el Cabildo, discutió sobre su rechazo y escribió al gobernador Henríquez para que suspendiese su ejecución (acta del Cabildo, 2 


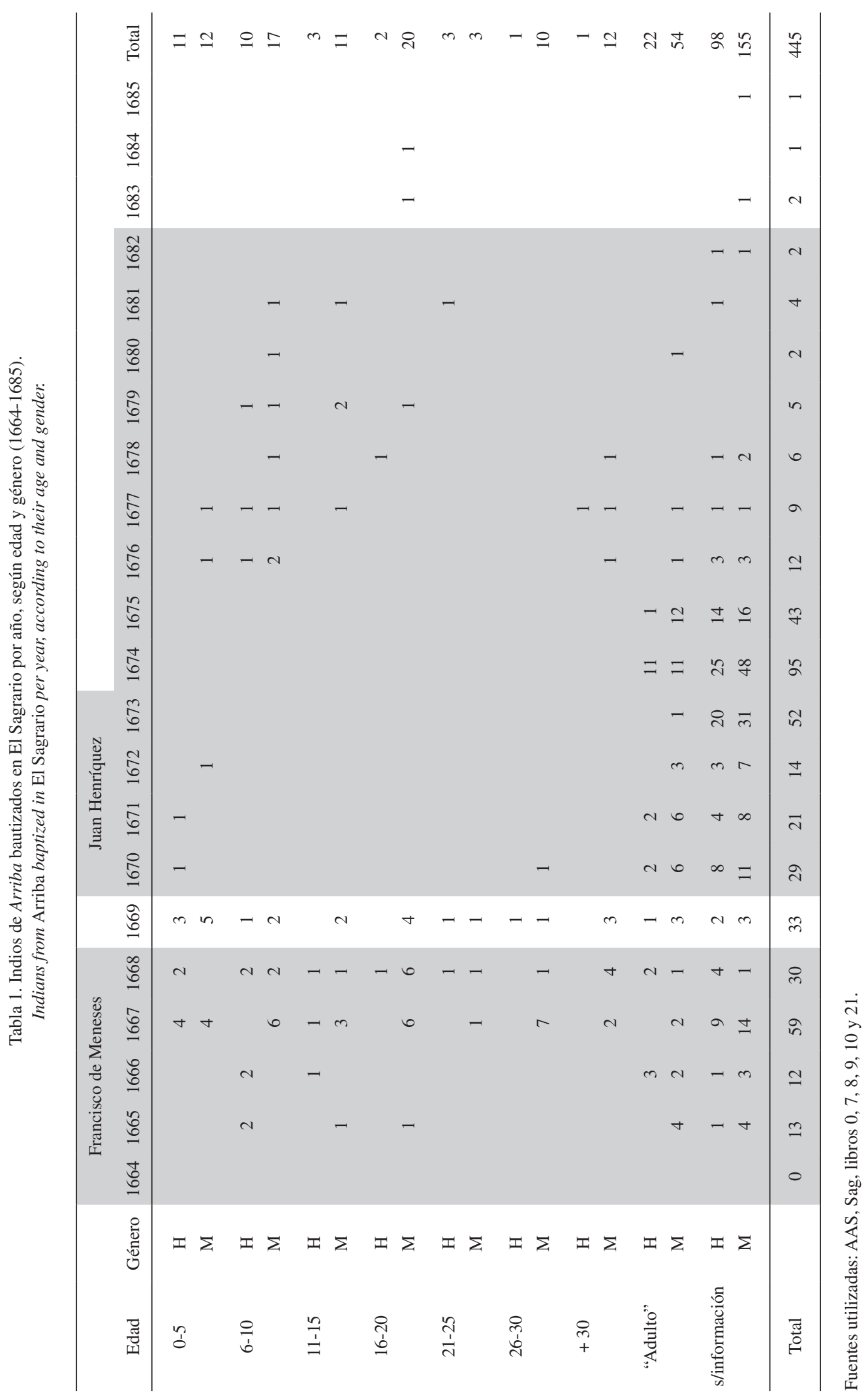


de noviembre de 1675, ACS, vol. 38, p. 479). Por lo demás, no solo siguen llegando indios forzados desde el sur, sino que también se mantienen los vocablos "esclavo" y auca para designarlos en las partidas de bautismo, incluso hasta fechas bien tardías en relación con las disposiciones abolicionistas.

La evidencia empírica nos muestra que la decadencia más tangible de estas prácticas y de la inmigración de "arribanos" a Santiago ocurriría después de 1680. Por ello sostenemos, siguiendo nuestra hipótesis central, que la coyuntura estudiada responde más bien a un período de transición, donde se cruzan las dinámicas demográficas, las prácticas laborales y los cambios legales, y que se cierra justamente en momentos en que se despliega en toda su magnitud la disponibilidad de la masa creciente de mestizos que se venía fraguando a lo largo de las décadas anteriores, junto con la implementación negociada de las disposiciones estatales que escalonaron el fin de la captura de indios esclavos... aunque no así la libertad de los que ya la vivían, que perpetuaron su condición gracias a la argucia legal del "depósito".

Agradecimientos: Este artículo forma parte del proyecto de investigación Fondecyt $\mathrm{N}^{\circ}$ 1100215: $L a$ diáspora mapuche en Chile colonial. Migraciones forzadas y voluntarias desde La Araucanía hacia el centro y norte de Chile y otras regiones del virreinato peruano (siglos XVI-XVIII). Versiones preliminares fueron presentadas en el "VIII Congreso internacional de etnohistoria" (Sucre, junio 2011) y en la " 5 a Jornada de investigaciones" del Laboratorio de Historia Colonial-UC (Santiago, diciembre 2012). Agradecemos a Patricia Palma y Katherine Quinteros, que revisaron y ficharon las partidas de bautismo de las parroquias de Santiago; a Alejandra Araya, por las referencias al juicio del gobernador Meneses; y a los evaluadores anónimos que hicieron observaciones y sugerencias al manuscrito original.

\section{Referencias Citadas}

\section{Documentos de archivos}

Actas del Cabildo de Santiago (ACS) 1898-1915. Actas capitulares del Cabildo de Santiago, publicadas en la Colección de historiadores de Chile y de documentos relativos a la historia nacional. Imprenta Elzeviriana, Santiago. Primera serie (15581705), vols. 33, 35, 37, 38 y 40.

Archivo del Arzobispado de Santiago (AAS): Parroquia del Sagrario (Sag), libros 0, 1, 2, 3, 6, 7, 8, 9, 10 y 21; Parroquia de Santa Ana (SA), libros 1, 2, 3 y 4.

Archivo General de Indias (AGI): Fondo Escribanía de Cámara (EC), sección 83, vol. 937.

Archivo Nacional Histórico de Chile (ANHCh): Fondo Capitanía General (CG), vol. 484: Fondo Real Audiencia (RA), vols. 2873 y 2905 .

Biblioteca Nacional de Chile (BNCh): Biblioteca Medina, Manuscritos (BMM), vols. 140, 141, 145 y 147.

\section{Fuentes publicadas}

Ariès, P. 1987 [1960]. El Niño y la Vida Familiar en el Antiguo Régimen. Taurus, Madrid.

Barros Arana, D. 1999-2005 [1884-1902]. Historia General de Chile. Universitaria / DIBAM, Centro de Investigaciones Diego Barros Arana, Santiago.

Bernand, C. 2001. Negros Esclavos y Libres en las Ciudades Hispanoamericanas. Fundación Histórica Tavera, Madrid.

Boccara, G. 2007 [1998]. Los Vencedores. Historia del Pueblo Mapuche en la Época Colonial. Universidad Católica del Norte, San Pedro de Atacama.
Carrasco, B. 1858 [1688]. Sinodos Diocesanos del Arzobispado de Santiago de Chile Celebrados por los Ilustrísimos Señores Doctor don fray Bernardo Carrasco Saavedra [1688] y Doctor don Manuel de Alday y Aspee [1763]. Eduardo Dunigan y hermano, New York.

Castillo, N. 2008. Cholula, Sociedad Mestiza en Ciudad India. Un análisis de las Consecuencias Demográficas, Económicas y Sociales del Mestizaje en una Ciudad Novohispana (16491796). Universidad Autónoma Metropolitana-Iztapalapa / Plaza y Valdés Editores, México D.F.

Contreras, H. 2005-2006. “Siendo mozetón o güeñi salió de su tierra a vivir entre los españoles". Migración y asentamiento mapuche en Chile central durante el siglo XVIII, 1700-1750". Historia Indígena 9:7-32.

Contreras, H. 2013. Indios de tierra adentro en Chile central: las modalidades de la migración forzosa y el desarraigo (fines del siglo XVI y principios del XVII). En América en Diásporas, Esclavitudes y Migraciones Forzadas (Siglos XVI-XIX), editado por J. Valenzuela, en prensa.

De Ramón, A. 1965. Bautizos de indígenas según los libros del Sagrario de Santiago correspondientes a los años 1581-1596. Historia 4:229-235.

----1978. Historia Urbana. Una Metodología Aplicada, CLACSO/ SIAP-Planteos, Buenos Aires.

----2000. Santiago de Chile (1541-1991). Historia de una Sociedad Urbana. Sudamericana, Santiago.

De Ramón, E. 2002. Obra y Fe. La Catedral de Santiago, 1541 1769. DIBAM, Santiago. 
Góngora, M. 1966. Vagabundaje y Sociedad Fronteriza en Chile (Siglos XVII a XIX), Universidad de Chile, Santiago.

Giudicelli, Ch. (ed.) 2011. Fronteras Movedizas. Clasificaciones Coloniales y Dinámicas Sociopolíticas en las Fronteras de las Américas. CEMCA / El Colegio de Michoacán, México D.F.

Hanisch, W. 1981. Esclavitud y libertad de los indios de Chile, 1598-1696. Historia 16:5-65.

Hoberman, L. y S. Socolow (eds.) 1992. Ciudades y Sociedad en Latinoamérica Colonial. Fondo de Cultura Económica, Buenos Aires.

Jara, A. 1984 [1961]. Guerra y Sociedad en Chile. Universitaria, Santiago.

Jara, A. y S. Pinto (comp.) 1982-1983. Fuentes para la Historia del Trabajo en el Reino de Chile. Legislación, 1546-1810. 2 vols. Andrés Bello, Santiago.

Konetzke, R. 1946. Documentos para la historia y crítica de los registros parroquiales en las Indias. Revista de Indias 7:581-586.

Lizana, E. (comp.) 1919. Colección de Documentos Históricos Recopilados del Archivo del Arzobispado de Santiago. vol. I. Imprenta de San José, Santiago.

Malone, M. 1989. Beyond the last frontier: Toward a new approach to Western American History. The Western Historical Quarterly 20:409-427.

Masferrer, C. 2011. Niños y niñas esclavos de origen africano en la capital novohispana (siglo XVII). En Debates Históricos Contemporáneos: Africanos y Afrodescendientes en México y Centroamérica, editado por M.E. Velázquez, pp. 195-242. INAH / UNAM / CEMCA / Institut de Recherche pour le Développement, México D.F.

Mellafe, R. 1986. Demografía histórica de América Latina. Fuentes y métodos. En Historia Social de Chile y América. Sugerencias y Aproximaciones, editado por R. Mellafe, pp. 146215. Universitaria, Santiago.

----1984 [1959]. La Introducción de la Esclavitud Negra en Chile. Tráfico y Rutas. Universitaria, Santiago.

Méndez, L.M. 1987. Trabajo indígena en la frontera araucana de Chile. Jahrbuch für Geschichte von staat, wirtchaft und gesellshaft Lateinamerikas 24:213-249.

Muñoz, J.G. 2003. La esclavitud indígena, el caso de Colchagua. Revista de Historia Social y de las Mentalidades 7/2:113-147.

Noli, E. 1998. Chinas y chinitas: mujer indígena y trabajo doméstico. En Temas de Mujeres. Perspectivas de Género, editado por el Centro de Estudios Históricos Interdisciplinarios sobre las Mujeres, pp. 257-272. Universidad Nacional de Tucumán, Tucumán.

Obregón, J. y J.M. Zavala 2009. Abolición y persistencia de la esclavitud indígena en Chile colonial: estrategias esclavistas en la frontera araucano-mapuche. Memoria Americana 17:7-31.

Ogass, C. 2014. Curas, amos y esclavos en una parroquia. Apuntes metodológicos para construir un padrón de propiedad de mano de obra de origen africano (Santiago de Chile, 1700-1720). En América en Diásporas, Esclavitudes y Migraciones Forzadas (Siglos XVI-XIX), editado por J. Valenzuela, en prensa.

Oliver, P. 2006. Dos perspectivas de la historiografía del castigo en España. En Contornos y Pliegues del Derecho. Homenaje a
Roberto Bergalli, editado por I. Rivera y H. Silveira, pp. 482486. Anthropos, Barcelona.

Prosperi, A. 2006. Battesimo e identità cristiana nella prima età moderna. En Salvezza delle Anime, Disciplina dei Corpi. Un Seminario sulla Storia del Battesimo, editado por A. Prosperi, pp. 1-65. Scuola Normale Superiore, Pisa.

Rabell, C. 1990. La Población Novohispana a la Luz de los Registros Parroquiales: Avances y Perspectivas de Investigación. UNAM, México D.F.

Real Academia Española 1734. Diccionario de la Lengua Castellana, en que se Explica el Verdadero Sentido de las Voces, su Naturaleza y Calidad, con las Phrases o Modos de Hablar, los Proverbios o Refranes, y otras Cosas Convenientes al Uso de la Lengua. Tomo 4. Imprenta de la Real Academia Española, Madrid.

Reséndez, A. 2014. La cruzada antiesclavista y las fronteras del imperio español, 1660-1690. En América en Diásporas, Esclavitudes y Migraciones Forzadas (Siglos XVI-XIX), editado por J. Valenzuela, en prensa.

Ruiz, C. 1998. Presencia de los mapuche-huilliche en Chile central en los siglos XVI-XVIII. Desarraigo y mestizaje. Boletín del Museo y Archivo Histórico Municipal de Osorno 4:1-71.

Ruiz-Esquide, A. 1993. Los Indios Amigos en la Frontera Araucana. DIBAM, Centro de Investigaciones Diego Barros Arana, Santiago.

Soto, R. 2011. Esclavas Negras en Chile Colonial. Bravo y Allende Editores, Santiago.

Urbina, X. 2009. La Frontera de Arriba en Chile Colonial. Interacción Hispano-indígena en el Territorio entre Valdivia y Chiloé e Imaginario de sus Bordes Geográficos, 1600-1800. Pontificia Universidad Católica de Valparaíso / DIBAM, Centro de Investigaciones Diego Barros Arana, Santiago.

Valenzuela, J. 2007. El terremoto de 1647: experiencia apocalíptica y representaciones religiosas en Santiago colonial. En Historias Urbanas. Homenaje a Armando de Ramón, editado por J. Valenzuela, pp. 27-65. Universidad Católica de Chile, Santiago.

----2009. Esclavos mapuches. Para una historia del secuestro y deportación de indígenas en la Colonia. En Historias de Racismo y Discriminación en Chile, editado por R. Gaune y M. Lara, pp. 225-260. Uqbar Editores, Santiago.

Vázquez de Espinosa, A. 1969 [c.1629]. Compendio y Descripción de las Indias Occidentales. Biblioteca de Autores Españoles, Madrid.

Villalobos, S. 1995. Vida Fronteriza en La Araucanía. El Mito de la Guerra de Arauco. Andrés Bello, Santiago.

Zúñiga, J.-P. 2002. Espagnols d'outre-mer. Émigration, Métissage et Reproduction Sociale à Santiago du Chili, au $17^{e}$ Siècle. École des Hautes Études en Sciences Sociales, Paris.

----2006. Histoire d'un oubli: l'apport africain au peuplement de Santiago du Chili au XVIIe siècle. En Mélanges en l'honneur de Nicole Moine et Claire Prévotat, pp. 115-132. Éditions Dominique Guéniot / Université de Reims, Langres. 


\section{Notas}

1 En el juicio a Meneses, ya citado, se encuentra la declaración de Melchor de Carvajal, donde se indica que en los cuatro años que duró aquella presidencia llegaron a Santiago, desde Concepción, un total de 182 "piezas" pertenecientes al gobernador, de las cuales se vendieron 146, obteniendo un total de 28.533 pesos (AGI, EC, sección 83, vol. 937, tercer cuaderno, fjs. 260 y 265). Si consideramos que el sueldo anual que percibía un gobernador de Chile en esos años era de unos 8.000 pesos (Barros Arana 1999-2005 [1884-1902]. 3:363-364), la venta de estos indios le habría permitido a Meneses más que doblar sus ingresos legales. Henríquez, por su parte, según la opinión de sus detractores recogida por el cronista Córdoba y Figueroa, habría transado para su beneficio directo entre 600 y 800 esclavos aucas a lo largo de los doce años de su presidencia, con los cuales, a un precio promedio de 250-300 pesos cada "pieza", podría haber incluso triplicado su salario (Villalobos 1995:98-99).

2 Desde 1635 funcionaba la parroquia de Santa Ana, con jurisdicción sobre el sector poniente de la ciudad, pero sus partidas de bautismo se consideraron como complemento general, ya que sus libros solo contienen fragmentos de partidas; de hecho, para las dos décadas que trabajamos únicamente se bautizaron allí siete "esclavas" y dos "de Arriba" (AAS, SA, libros 2, 3 y 4). Desde 1662 funcionan otras dos parroquias para las periferias del norte y este de la ciudad -Renca y Ñuñoa-. Los datos de esta última aún no los hemos recensado, mientras que los de Renca mantienen la tendencia que consignamos para Santa Ana.

3 A la fecha del terremoto de 1647 el radio propiamente urbano de la capital tendría unos 4.000 habitantes. A comienzos del siglo XVII el distrito de Santiago -la ciudad y su comarca- estaría poblado por unos 11.000 habitantes, de los cuales 2.000 serían hispanocriollos y entre los otros 9.000 se repartirían indios, negros y "castas". Para ese mismo distrito, hacia 1614 el oidor Machado apuntaba un total de 2.345 indígenas, mientras que el historiador Barros Arana afirma que hacia 1630 no serían menos de 3.000 sus habitantes de origen español (Vázquez de Espinosa, 1969 [c.1629]:45; De Ramón 2000:49-75; Barros Arana 19992005 [1884-1902], IV:284).

4 El impuesto de balanza gravaba cada quintal de "productos de la tierra" cargados en el puerto de Valparaíso.

5 Así lo reclamaban, por ejemplo, varios asentistas de cuerdas para el ejército, que en 1663 solicitaban a la Audiencia no se les quitasen los indios de sus encomiendas -que eran expertos en la fabricación de ese producto- para ir a trabajar en la construcción de la catedral (causa de Antonio de Puebla y otros, Santiago, 1663, ANHCh, RA, vol. 2873, fjs. 212-217v). Agradecemos a Hugo Contreras por esta referencia.

6 Desde el siglo XVI se articula de manera más explícita la antigua costumbre estatal de sentenciar a los reos a servir forzosa y gratuitamente a la Corona, destinándolos a las galeras, presidios, minas y, a partir de la segunda mitad del XVIII, al trabajo en obras públicas, en un mecanismo que Pedro Oliver denomina “utilitarismo punitivo". Desde esta perspectiva, el trabajo forzado no solo integra la variante de castigo, sino que la relaciona con la regulación estatal del mercado de trabajo y el control social (Oliver 2006).

7 La misma cédula que legalizó la esclavitud en 1608 estipulaba un límite de edad muy bajo para poder ser capturado y vendido, pues los hombres podían serlo desde poco más de 10 años y las mujeres desde los 9 y medio. Pero los niños menores de esas edades también podían ser secuestrados y deportados, con el fin de que fuesen entregados a personas que los cristianizaran, estando obligados a servirles -teóricamente- hasta los 20 años (Jara y Pinto 1982-1983, 1:254256). De hecho, los registros notariales de compraventas en Chile central se poblaron de hueñis y de chinas, y se hizo costumbre que los militares-estancieros que volvían de sus campañas araucanas trajeran consigo algunos niños para incorporarlos a las labores de su propiedad, como criados en sus casas, o para regalarlos a parientes y amigos (Muñoz 2003:116-117). 